JURNAL RISET REKAYASA ELEKTRO

Vol.1, No.2, Desember 2019, Hal. 110 118

P-ISSN: 2685 - 4341

E-ISSN: 2685 - 5313

\title{
Analisis Koordinasi Pengaman Over Current Relay, Ground Fault Relay, Dan Recloser Pada Penyulang Majenang 08 PT. PLN (Persero) Gardu Induk Majenang Cilacap
}

Tri Juniarto ${ }^{1}$, Muhammad Taufiq Tamam²

Program Studi S1 Teknik Elektro, Universitas Muhammadiyah Purwokerto

Fakultas Teknik dan Sains, Universitas Muhammadiyah Purwokerto

\section{Informasi Makalah}

Dikirim, 21 Agustus 2019

Direvisi, 27 November 2019

Diterima, 16 Januari 2020

\section{Kata Kunci:}

Buck Converter

Lead Acid

Li-Ion

Mikrokontroler

Panel Surya

\section{INTISARI}

Sistem distribusi tenaga listrik adalah sistem yang berguna untuk mendistribusikan tenaga listrik dari Gardu Induk ke konsumen, yang mana tidak terlepas dari masalah, diantaranya gangguan arus hubung singkat. Untuk melokalisasi gangguan tersebut diperlukan sistem proteksi yang memenuhi persyaratan sensitifitas, keandalan, selektifitas dan kecepatan. Penyulang MJN 08 memiliki panjang 32,950 km terdapat over current relay (OCR) dan ground fauly relay (GFR) yang berfungsi untuk memberi perintah kepada Recloser atau PMT. Pada penelitian gangguan arus hubung singkat dan koordinasi proteksi di penyulang MJN 08 dilakukan perhitungan manual dan simulasi menggunakan ETAP. Hasil perhitungan dan simulasi arus hubung singkat diketahui bahwa semakin jauh titik gangguan yang terjadi maka arus hubung singkat akan semakin kecil. Hasil perhitungan manual koordinasi proteksi waktu kerja relai arus hubung singkat 3 fasa adalah 0,301 detik - 0,534 detik dan pada simulasi dengan ETAP 0,303 detik - 0,532 detik, pada perhitungan manual arus hubung singkat 2 fasa 0,331 detik 0,755 detik, dan simulasi ETAP 0,319 detik - 0,582 detik. Waktu kerja OCR sudah mendekati standar SPLN yaitu 0,35 detik - 0,4 detik, tetapi mempunyai selisih waktu lebih lambat 0,1 detik. Hasil perhitungan manual hubung singkat 1 fasa ke tanah 0,765 detik - 1,496 detik sedangkan pada simulasi ETAP adalah 0,706 detik - 1,243 detik. Dari hasil perhitungan dan simulasi nilai waktu kerja proteksi GFR belum sesuai dengan SPLN.

\begin{abstract}
Electric power distribution system is a system that is useful for distributing electric power from substations to consumers, which are inseparable from problems, including short circuit current interference. To localize the interference, a protection system is needed that meets the requirements of sensitivity, reliability, selectivity and speed. MJN 08 feeders have a length of $32.950 \mathrm{~km}$ with over current relay (OCR) and ground fauly relay (GFR) that serve to give orders to Reclosers or PMT. In the study of short circuit current and protection coordination in MJN 08 feeders manual calculations and simulations using ETAP were performed. The results of calculations and simulations of short circuit currents are known that the farther the point of disturbance that occurs, the short circuit current will be smaller. The results of the protective coordination manual calculation of the 3 phase short circuit current relay work time are 0.301 seconds - 0.534 seconds and in the simulation with ETAP 0.303 seconds - 0.532 seconds, while the manual calculation of 2 phase short circuit current is 0.331 seconds -0.755 seconds, and ETAP simulation is 0.319 seconds - 0.582 seconds. OCR working time is approaching the SPLN standard, which is 0.35 seconds - 0.4 seconds, but has a difference of 0.1 seconds slower. The results of manual 1-to-ground short circuit calculation are 0.765 seconds -1.496 seconds while ETAP simulation is 0.706 seconds -1.243 seconds. From the results of calculations and simulations the value of GFR protection work time is not in accordance with the SPLN.
\end{abstract}


Korespondensi Penulis:

Tri Juniarto

Program Studi S1 Teknik Elektro

Universitas Muhammadiyah Purwokerto

Jl Raya Dukuhwaluh, Purwokerto, 53182

Email: trijuniarto098@gmail.com

\section{PENDAHULUAN}

Dalam melaksanakan pembangkitan, penyalutan, dan distribusi tenaga listrik, gangguan tidak dapat dihindari. Gangguan kebanyakan merupakan gangguan hubung singkat antar fasa atau antar fasa dengan tanah dan keduanya. Gangguan hubung singkat semacam ini menimbulkan arus yang sangat besar yang dapat merusak peralatan sehingga diperlukan sistem proteksi untuk mengamankan peralatan tersebut. Sistem proteksi selain harus mengamankan peralatan instalasi terhadap gangguan, juga berfungsi melokalisir gangguan. Apabila terjadi gangguan di suatu bagian istalasi, sistem proteksi hanya akan mentrip PMT yang berdekatan dengan gangguan sehingga intrupsi pasokan daya dapat dilakukan di sekitar tempat terjadinya gangguan tidak meluas (Marsudi, 2005).

Salah satu permasalahan yang sering terjadi adalah pada sistem distribusi sisi penyulang $20 \mathrm{kV}$ dimana gangguan tersebut diakibatkan dari adanya gangguan arus hubung singkat. Jika setting pengaman pada outgoing feeder kurang baik maka gangguan arus hubung singkat dapat memutuskan pengaman yang berada di incoming feeder sehingga dapat menyebabkan pemadaman di seluruh penyulang, dan apabila gangguan arus hubung singkat tidak bisa diatasi maka akan mengurangi kehandalan sistem, merusak peralatan, dan menurunkan kepercayaan konsumen yang dapat menyebabkan kerugian perusahaan.

\section{METODE PENELITIAN}

Penelitian dilakukan untuk menunjukan tahapan-tahapan penelitian yang dilakukan pada penyulang MJN 08 PT. PLN (Persero) Gardu Induk Majenang, di tunjukan pada Gambar 1.

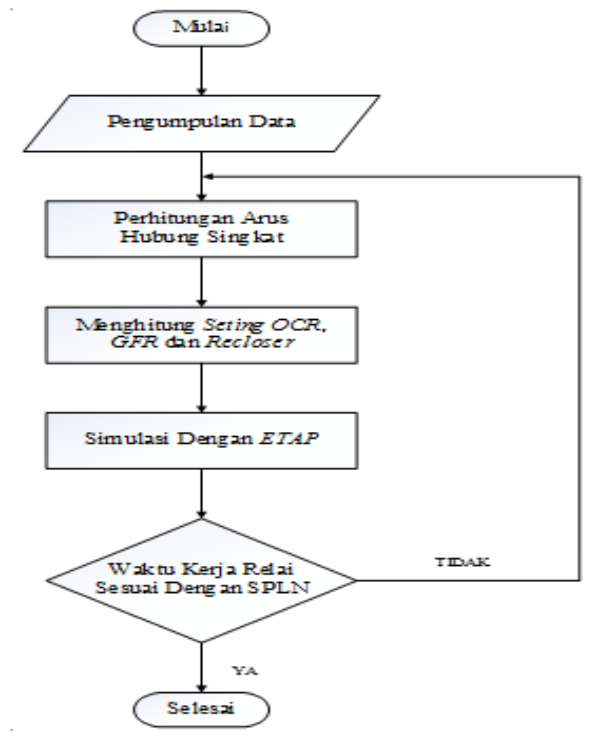

Gambar 1. Flowchart Penelitian

\section{Penjelasan}

1. Pengambil data di Gardu Induk Majenang dan UP3 cilacap, mengambil data transformator tenaga, data penghantar salaluran tegangan menengah, data proteksi PMT dan recloser, data gangguan yang terjadi di penyulang MJN 08.

2. Menghitung secara manul perhitungan arus hubung singkat tiga fasa, dua fasa,dan satu fasa, setelah menghitung arus hubung singkat dan menghitung seting over current relay (OCR) dan ground fault relay $(\mathrm{GFR})$ 
3. Mensimulasikan gangguan hubung singkat tiga fasa, dua fasa dan satu fasa ke tanah dengan asumsi gangguan $10 \%, 20 \%, 30 \%, 40 \%, 50 \%, 60 \%, 70 \%, 80 \%, 90 \%$ dan 100\% menggunakan Software ETAP.

4. Mensimulasikan waktu kerja koordinasi proteksi dari asimsi jarak gangguan $10 \%, 20 \%, 30 \%, 40 \%$, $50 \%, 60 \%, 70 \%, 80 \%, 90 \%$ dan $100 \%$ menggunakan Software ETAP.

5. Membandingkan waktu kerja koordinasi proteksi sudah sesuai dengan SPLN 64 : 1985.

Berdasarkan studi kasus yang dihadapi, maka pada skripsi ini akan membahas tentang analisis koordinasi pengaman over current relay, ground fault relay, dan recloser pada jaringan $20 \mathrm{kV}$. Dalam pengambilan data sampai analisis hasil yang dilakukan melalui beberapa tahapan seperti Gambar 2 .

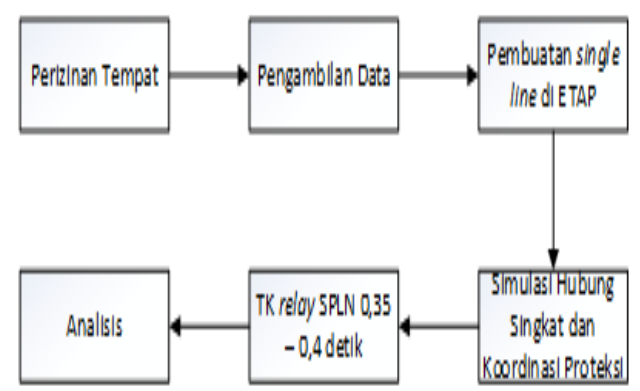

Gambar 2. Flowchart Pengisi Baterai

\section{HASIL DAN PEMBAHASAN}

Gardu Induk Majenang 150 kV terletak di Desa Cilopadang, kecamatan Majenang, merupakan salah satu Gardu Induk pasangan luar dengan tegangan 150/20 kV dimana tegangan sisi primer sebesar 150 $\mathrm{kV}$ dan tegangan sisi sekunder sebesar $20 \mathrm{kV}$. Pada penelitian ini penulis akan meneliti penyulang MJN 08 Gardu Induk Majenang yang terhubung dengan transformator III kapasitas 60 MVA.

Tabel 1. Data Spesifikasi Trafo III (Sumber : Gardu Induk Majenang)

\begin{tabular}{ll}
\hline Gardu Induk & Majenang \\
\hline No. Trafo & III \\
\hline Merk & Unindo \\
\hline No.Serial & P060LEC 764-09 \\
\hline Tegangan & $150 / 20 \mathrm{kV}$ \\
\hline Frekuensi & $50 \mathrm{~Hz}$ \\
\hline Kapasitas & $60 \mathrm{MVA}$ \\
\hline Arus Hubung Singkat 3 Fasa & $13.493 \mathrm{kA}$ \\
\hline Arus Hubung Singkat 150kV & $3505,6 \mathrm{MVA}$ \\
\hline Arus Nominal Trafo & $1732 \mathrm{~A}$ \\
\hline Impedansi Urutan Positif/Negatif & $0,1344+\mathrm{j} 0,3158$ \\
\hline Impedansi Urutan Nol & $0,3631+\mathrm{j} 1,6180$ \\
\hline Impedansi Trafo & $12,23 \%$ \\
\hline Jenis Pendingin & ON AN/ ONAF \\
\hline Belitan Tarfo & YnYno+d \\
\hline Tahun Operaso & 2016 \\
Pentanahan & Solid \\
\hline
\end{tabular}

Tabel 2. Data Spesifikasi Penghantar MJN 08 (Sumber : UP3 Cilacap)

\begin{tabular}{ll}
\hline Sumber Tenaga & Trafo III Majenang 60 MVA \\
\hline Peralattan Proteksi Terpasang & 1 PMT Outgoing dan 2 recloser \\
\hline Panjang Penyulang & $32,950 \mathrm{~km}$ \\
\hline Jenis Kabel saluran & Aluminium AAAC $240 \mathrm{~mm}^{2}$ \\
\hline Impedansi Saluran & Urutan Positif/negative $: 0,1344+\mathrm{j} 0,3158$ \\
& Urutan nol : $0,3631+\mathrm{j} 1,6180$ \\
\hline
\end{tabular}


Tabel 3. Data Spesifikasi PMT (Sumber : UP3 Cilacap)

\begin{tabular}{llll}
\hline \multicolumn{3}{c}{ Merek PMT } & \multicolumn{1}{c}{ Schneider } \\
\hline \multicolumn{3}{c}{ Media peredam } & \multicolumn{1}{c}{ SF 6 } \\
\hline \multicolumn{3}{c}{ Relay PMT } \\
\hline \multicolumn{3}{c}{ Over Current Relay } & \multicolumn{2}{c}{ Ground Fault Relay } \\
\hline Ratio $C T$ & $600 / 5 \mathrm{~A}$ & Ratio CT & $600 / 5 \mathrm{~A}$ \\
Kurva & SI & Kurva & SI \\
Tms & 0,15 & Tms & 0,3 \\
Iset primer & $480 \mathrm{~A}$ & Iset primer & $200 \mathrm{~A}$ \\
Iset sekunder & $3480 \mathrm{~A}$ & Iset sekunder & 2598 \\
\hline
\end{tabular}

Tabel 4. Data Spesifikasi Recloser 1 (Sumber : UP3 Cilacap)

\begin{tabular}{llll}
\hline \multicolumn{2}{c}{ Over Current Relay $($ OCR) } & \multicolumn{2}{c}{ Ground Fault Relay $($ GFR) } \\
\hline Merek & Schneider ADVC & Merek & Schneider ADVC \\
Ratio CT & $1000 / 1$ & Ratio CT & $1000 / 1$ \\
Kurva & IEC SI & Kurva & IEC SI \\
Tms & 0,08 & Tms & 0,13 \\
Iset primer & $400 \mathrm{~A}$ & Ioset primer & $130 \mathrm{~A}$ \\
Iset sekunder & 2400 & Ioset sekunder & 1300
\end{tabular}

Tabel 5. Data Spesifikasi Recloser 2 (Sumber : UP3 Cilacap)

\begin{tabular}{llll}
\hline \multicolumn{2}{c}{ Over Current Relay $($ OCR $)$} & \multicolumn{2}{c}{ Ground Fault Relay $($ GFR $)$} \\
\hline Merek & ENTEC EVRC2A & Merek & ENTEC EVRC2A \\
Ratio CT & $500 / 1$ & Ratio CT & $500 / 1$ \\
Kurva & IEC SI & Kurva & IEC SI \\
Tms & 0,05 & Tms & 0,1 \\
Iset primer & $360 \mathrm{~A}$ & Ioset primer & $110 \mathrm{~A}$ \\
Iset sekunder & $1270 \mathrm{~A}$ & Ioset sekunder & $597 \mathrm{~A}$ \\
\hline
\end{tabular}

Pada penelitian ini perhitungan arus gangguan akan dihitung dengan asumsi jarak gangguan terjadi pada $10 \%, 20 \%, 30 \%, 40 \%, 50 \%, 60 \%, 70 \%, 80 \%, 90 \%$, dan $100 \%$ dari panjang penyulang. Pembagian asumsi gangguan berdasarkan letak dari PMT dan recloser sehingga nanti dapat diketahui bagaimana kerja dari PMT, recloser 1 dan recloser 2. Arus gangguan yang akan dihitung adalah arus gangguan hubung singkat tiga fasa, dua fasa, dan satu fasa ke tanah.

Arus nominal pada sisi $150 \mathrm{kV}$

In $150 \mathrm{kV}=\frac{\mathrm{MVA}}{\mathrm{kV} \cdot \sqrt{3}}=\frac{60.000}{150 \cdot \sqrt{3}}=230,94$ Ampere

Arus nominal pada sisi $20 \mathrm{kV}$

In $20 \mathrm{kV}=\frac{\text { MVA }}{k V \cdot \sqrt{3}}=\frac{60.000}{20 \cdot \sqrt{3}}=1732,05$ Ampere

Reaktansi sumber pada sisi $150 \mathrm{kV}$

$\mathrm{Xs} 150 \mathrm{kV}=\frac{k V^{2}}{M V A H S}=\frac{150^{2}}{3505,6}=6.418 \mathrm{Ohm}$

Reaktansi sumber pada sisi $20 \mathrm{kV}$

$\mathrm{Xs} 20 \mathrm{kV}=\frac{k V^{2}}{M V A H S}=\frac{20^{2}}{3505,6}=0,114 \mathrm{Ohm}$

a. Impedansi Urutan Positif, Negatif

$Z 1=Z 2=Z$ positif $x$ panjang penyulang $Z 1=Z 2=(0,1344+\mathrm{j} 0,3158) \Omega / \mathrm{km} \times 32,950 \mathrm{~km}$

$Z 1=Z 2=4,428+\mathrm{j} 10,405$ 
Tabel 6. Nilai Impedansi Urutan Positif, Negatif

\begin{tabular}{|c|c|}
\hline Jarak \% & $\mathbf{Z 1}=\mathbf{Z 2}$ \\
\hline 10 & $10 \%(4,428+\mathrm{j} 10,405)=0,442+\mathrm{j} 1,040$ \\
\hline 20 & $20 \%(4,428+\mathrm{j} 10,405)=0,885+\mathrm{j} 2,081$ \\
\hline 30 & $30 \%(4,428+j 10,405)=1,328+j 3,121$ \\
\hline 40 & $40 \%(4,428+\mathrm{j} 10,405)=1,771+\mathrm{j} 4,162$ \\
\hline 50 & $50 \%(4,428+\mathrm{j} 10,405)=2,214+\mathrm{j} 5,202$ \\
\hline 60 & $60 \%(4,428+j 10,405)=2,656+j 6,243$ \\
\hline 70 & $70 \%(4,428+j 10,405)=3,099+j 7,283$ \\
\hline 80 & $80 \%(4,428+j 10,405)=3,542+j 8,324$ \\
\hline 90 & $90 \%(4,428+j 10,405)=3,985+j 9,364$ \\
\hline 100 & $100 \%(4,428+\mathrm{j} 10,405)=4,428+\mathrm{j} 10,405$ \\
\hline
\end{tabular}

b. Impedansi Urutan Nol

$Z 0=\mathrm{Z}$ urutan nol kabel $\mathrm{x}$ jarak penyulang

$Z 0=(0,3631+\mathrm{j} 1,6180) \Omega / \mathrm{km} \times 32,950 \mathrm{~km}$

$Z 0=11,964+\mathrm{j} 53,313$

Tabel 7. Nilai Impedansi Urutan Nol

\begin{tabular}{ccc}
\hline Jarak \% & Z0 (Ohm) \\
\hline 10 & $10 \%$ & $(11,964+\mathrm{j} 53,313)=1,196+\mathrm{j} 5,331$ \\
20 & $20 \%$ & $(11,964+\mathrm{j} 53,313)=2,392+\mathrm{j} 10,662$ \\
30 & $30 \%$ & $(11,964+\mathrm{j} 53,313)=3,589+\mathrm{j} 15,993$ \\
40 & $40 \%$ & $(11,964+\mathrm{j} 53,313)=4,785+\mathrm{j} 21,325$ \\
50 & $50 \%$ & $(11,964+\mathrm{j} 53,313)=5,982+\mathrm{j} 26,656$ \\
60 & $60 \%$ & $(11,964+\mathrm{j} 53,313)=7,178+\mathrm{j} 31,987$ \\
70 & $70 \%$ & $(11,964+\mathrm{j} 53,313)=8,374+\mathrm{j} 37,319$ \\
80 & $80 \%$ & $(11,964+\mathrm{j} 53,313)=9,571+\mathrm{j} 42.650$ \\
90 & $90 \%$ & $(11,964+\mathrm{j} 53,313)=10,767+\mathrm{j} 47,981$ \\
100 & $100 \% .(11,964+\mathrm{j} 53,313)=11,964+\mathrm{j} 53.313$ \\
\hline
\end{tabular}

a. Impedansi Ekivalen Urutan Positif, Negatif

$\mathrm{Z} 1,2 \mathrm{eq}=\mathrm{Z}+X s 20 k v+X t 1=\mathrm{Z}+\mathrm{j} 0,114+\mathrm{j} 0,815$

Tabel 8. Nilai Impedansi ekivalen Urutan Positif, Negatif

\begin{tabular}{ccl}
\hline Jarak \% & Z1eq $=$ Z2eq $($ Ohm $)$ \\
\hline 10 & $(0,442+\mathrm{j} 1,040)+\mathrm{j} 0,114+\mathrm{j} 0,815=(0,442+\mathrm{j} 1,969)$ & $=2,018$ \\
20 & $(0,885+\mathrm{j} 2,081)+\mathrm{j} 0,114+\mathrm{j} 0,815=(0,885+\mathrm{j} 3,01)$ & $=3,137$ \\
30 & $(1,328+\mathrm{j} 3,121)+\mathrm{j} 0,114+\mathrm{j} 0,815=(1,328+\mathrm{j} 4,05)$ & $=4,262$ \\
40 & $(1,771+\mathrm{j} 4,162)+\mathrm{j} 0,114+\mathrm{j} 0,815=(1,771+\mathrm{j} 5,091)$ & $=5,390$ \\
50 & $(2,214+\mathrm{j} 5,202)+\mathrm{j} 0,114+\mathrm{j} 0,815=(2,214+\mathrm{j} 6,131)$ & $=6,518$ \\
60 & $(2,656+\mathrm{j} 6,243)+\mathrm{j} 0,114+\mathrm{j} 0,815=(2,656+\mathrm{j} 7,172)$ & $=7,648$ \\
70 & $(3,099+\mathrm{j} 7,283)+\mathrm{j} 0,114+\mathrm{j} 0,815=(3,099+\mathrm{j} 8,212)$ & $=8,777$ \\
80 & $(3,542+\mathrm{j} 8,324)+\mathrm{j} 0,114+\mathrm{j} 0,815=(3,542+\mathrm{j} 9,253)$ & $=9,907$ \\
90 & $(3,985+\mathrm{j} 9,364)+\mathrm{j} 0,114+\mathrm{j} 0,815=(3,985+\mathrm{j} 10,293)$ & $=11,037$ \\
100 & $(4,428+\mathrm{j} 10,405)+\mathrm{j} 0,114+\mathrm{j} 0,815=(4,428+\mathrm{j} 11,364)=12,196$ \\
\hline
\end{tabular}


b. Impedansi Ekivalen Urutan Nol

$$
\begin{aligned}
Z 0 e q= & \mathrm{Z} 0+\mathrm{Xt} 1=\mathrm{Z} 0+\mathrm{j} 0,815 \\
Z 0 e q=\mathrm{Z} 0 & +3 \mathrm{RN}+\mathrm{Zt} 0 \\
& =2,445+(3 \times 0,15)+\mathrm{Z} 0 \text { penyulang } \\
& =2,445+0,45+\mathrm{Z} 0
\end{aligned}
$$

Tabel 9. Nilai Ekivalen Impedansi Urutan Nol

\begin{tabular}{ccc}
\hline Jarak \% & Z0eq $=\mathbf{Z 0}+\mathbf{3 R N}+\mathbf{Z t 0}$ & \\
\hline 10 & $1,196+\mathrm{j} 5,331+(0,45)+\mathrm{j} 2,445=(1,646+\mathrm{j} 7,776)$ & $=7,948$ \\
20 & $2,392+\mathrm{j} 10,662+(0,45)+\mathrm{j} 2,445=(2,842+\mathrm{j} 13,107)$ & $=13,411$ \\
30 & $3,589+\mathrm{j} 15,993+(0,45)+\mathrm{j} 2,445=(4,039+\mathrm{j} 18,438)$ & $=18,874$ \\
40 & $4,785+\mathrm{j} 21,325+(0,45)+\mathrm{j} 2,445=(5,235+\mathrm{j} 23,377)$ & $=23,955$ \\
50 & $5,982+\mathrm{j} 26,656+(0,45)+\mathrm{j} 2,445=(6,432+\mathrm{j} 29,101)$ & $=29,803$ \\
60 & $7,178+\mathrm{j} 31,987+(0,45)+\mathrm{j} 2,445=(7,628+\mathrm{j} 34,432)$ & $=35.258$ \\
70 & $8,374+\mathrm{j} 36,319+(0,45)+\mathrm{j} 2,445=(8,824+\mathrm{j} 38,764)$ & $=39,755$ \\
80 & $9,571+\mathrm{j} 42.650+(0,45)+\mathrm{j} 2,445=(10,021+\mathrm{j} 45,095)$ & $=46,195$ \\
90 & $10,767+\mathrm{j} 47,981+(0,45)+\mathrm{j} 2,445=(11,217+\mathrm{j} 50,426)=51,658$ \\
100 & $11,964+\mathrm{j} 53,313+(0,45)+\mathrm{j} 2,445=(12,414+\mathrm{j} 55,758)=57,123$ \\
\hline
\end{tabular}

Setelah mendapatkan impedansi ekivalen sesuai dengan lokasi gangguan, selanjutnya perhitungan arus gangguan hubung singkat dapat digitung dengan menggunakan rumus dasar seperti dijelaskan sebelumnya, hanya saja impedansi ekivalen mana yang dimasukkan ke dalam rumus dasar tersebut adalah

\begin{tabular}{|c|c|c|c|}
\hline $\begin{array}{c}\text { Jarak } \\
(\%)\end{array}$ & Rumus & $\begin{array}{c}\text { Zeq positif } \\
\text { negatif }(\mathrm{Ohm})\end{array}$ & $\begin{array}{c}\text { Ihsc } 3 \text { Fasa } \\
\text { (A) }\end{array}$ \\
\hline 10 & \multirow{10}{*}{ Ihsc 3 Fasa $=\frac{11547}{\text { Zeq positif }}$} & 2,018 & 5722,001 \\
\hline 20 & & 3,137 & 3680,905 \\
\hline 30 & & 4,262 & 2709,291 \\
\hline 40 & & 5,390 & 2142,300 \\
\hline 50 & & 6,518 & 1771,555 \\
\hline 60 & & 7,648 & 1509,806 \\
\hline 70 & & 8,777 & 1315,597 \\
\hline 80 & & 9,907 & 1165,539 \\
\hline 90 & & 11,037 & 1046,208 \\
\hline 100 & & 12,196 & 946,785 \\
\hline
\end{tabular}
tergantung dari jenis gangguan hubung singkatnya, dimana gangguan hubung singkat tersebut bisa gangguan hubung singkat 3 fasa, 2 fasa atau 1 fasa ke tanah

Tabel 10. Arus Hubung Singkat 3 Fasa 
Tabel 11. Arus Hubung Singkat 2 Fasa

\begin{tabular}{cccc}
\hline $\begin{array}{c}\text { Jarak } \\
(\%)\end{array}$ & Rumus & $\begin{array}{c}\text { Zeq positif } \\
\text { negatif } \\
(\mathbf{O h m})\end{array}$ & $\begin{array}{c}\text { Ihsc 2 Fasa } \\
\text { (A) }\end{array}$ \\
\hline 10 & & 2,018 & 4955,401 \\
20 & & 3,137 & 3187,759 \\
30 & Ihsc2 Fasa & 4,262 & 2346,316 \\
40 & 20000 & 5,390 & 1855,287 \\
50 & & 6,518 & 1534,212 \\
60 & & 7,648 & 1307,531 \\
70 & & 8,777 & 1139,341 \\
80 & & 9,907 & 1009,998 \\
90 & & 11,037 & 906.043 \\
100 & & 12,196 & 819,940 \\
\hline
\end{tabular}

Tabel 12. Arus Hubung Singkat 1 Fasa

\begin{tabular}{|c|c|c|c|c|}
\hline $\begin{array}{c}\text { Jarak } \\
(\%)\end{array}$ & Rumus & $\begin{array}{l}\text { Zeq positif } \\
\text { negatif } \\
(\text { Ohm })\end{array}$ & $\begin{array}{c}\text { Zeq nol } \\
\text { (Ohm) }\end{array}$ & $\begin{array}{c}\text { Ihsc } 1 \\
\text { Fasa } \\
\text { (A) }\end{array}$ \\
\hline 10 & \multirow{10}{*}{$\begin{array}{l}\text { Ihsc } 1 \text { Fasa }= \\
3 \times\left(\frac{20000 / \sqrt{3}}{\text { Zeq positif }+ \text { Zeq negatif }+ \text { Zeq nol }}\right)\end{array}$} & 2,018 & 7,948 & 2890,604 \\
\hline 20 & & 3,137 & 13,411 & 1759,766 \\
\hline 30 & & 4,262 & 18,874 & 1264,362 \\
\hline 40 & & 5,390 & 23,955 & 997,293 \\
\hline 50 & & 6,518 & 29,803 & 808,632 \\
\hline 60 & & 7,648 & 35.258 & 685,227 \\
\hline 70 & & 8,777 & 39,755 & 604,460 \\
\hline 80 & & 9,907 & 46,195 & 524,792 \\
\hline 90 & & 11,037 & 51,658 & 459,823 \\
\hline 100 & & 12,196 & 57,123 & 424,964 \\
\hline
\end{tabular}

Analisis Arus Hubung Singkat

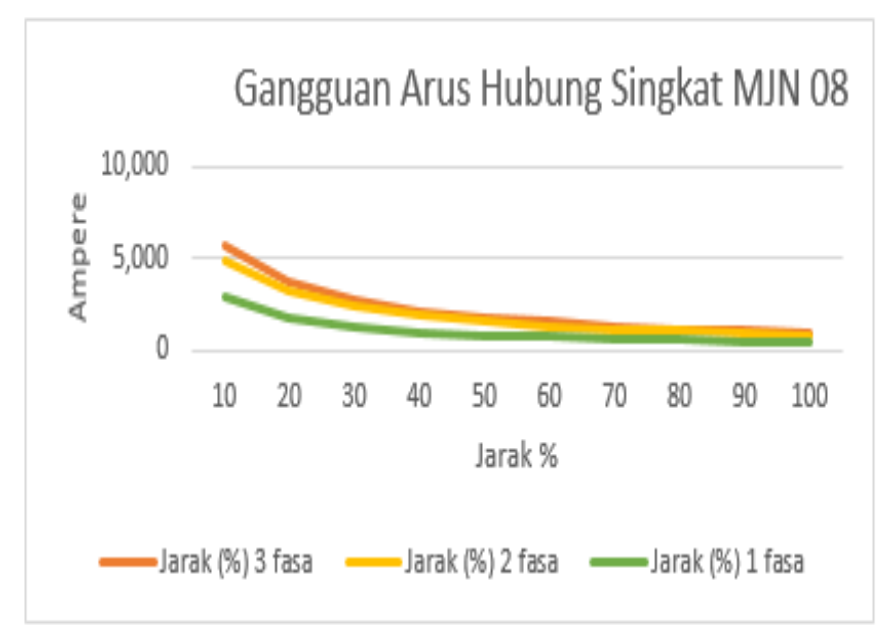

Gambar 3. Grafik Arus Hubung Singkat 
Pada arus hubung singkat tiga fasa jarak asumsi gangguan $10 \%$ didapat nilai arus hubung singkat 5722 A, jarak 50\% di dapat 1771 A dan pada jarak 100\% nilai arus hubung singkatnya 946 A. Begitu pula pada arus hubung singkat dua fasa dan satu fasa ke tanah. nilai arus hubung singkat dari hasil perhitungan pada penyulang MJN 08, dapat disimpulkan bahwa semakin jauh jarak titik gangguan maka nilai arus hubung singkat akan semakin kecil.

Hasil untuk mengetahui koordinasi OCR (Over current relay) tiga fasa, maka dari itu akan dilakukan mencari selisih waktu kerja dari kedua OCR pada asumsi jarak ganguan $(10 \%, 20 \%, 30 \%, 40 \%, 50 \%, 60 \%, 70 \%, 80 \%$, 90\% dan 100\%). Pada asumsi jarak gangguan $10 \%$ - 30\% wilayah kerja PMT, pada asumsi jarak gangguan $40 \%$ - $60 \%$ masuk wilayah kerja Recloser 1 dan asumsi jarak gangguan 70\% - 100\% wilayah kerja Recloser 2.

Tabel 13. Perbandingan Arus Hubung Singkat (Ihc) Perhitungan dan Simulasi koordinasi

\begin{tabular}{cccc}
\hline \multirow{2}{*}{ Jarak (\%) } & \multicolumn{3}{c}{ Arus Hubung Singkat (A) } \\
& 3 Fasa & 2 Fasa & 1 Fasa \\
\hline 10 & 5722,001 & 4955,401 & 2890,604 \\
20 & 3680,905 & 3187,759 & 1759,766 \\
30 & 2709,291 & 2346,316 & 1264,362 \\
40 & 2142,300 & 1855,287 & 997,293 \\
50 & 1771,555 & 1534,212 & 808,632 \\
60 & 1509,806 & 1307,531 & 685,227 \\
70 & 1315,597 & 1139,341 & 604,460 \\
80 & 1165,539 & 1009,998 & 524,792 \\
90 & 1046,208 & 906,043 & 459,823 \\
100 & 946,785 & 819,940 & 424,964 \\
\hline
\end{tabular}

Dapat kita lihat pada Tabel 13 perbandingan antara nilai gangguan arus hubung singkat perhitungan dan simulasi koordinasi. Nilai keduanya saling berbeda, hal ini dapat terjadi karena perhitungan yang digunakan manual dan simulasi dengan software ETAP memiliki metode pembulatan angka yang berbeda, sehingga akan ada perbedaan hasil hitung.

Tabel 14. Perbandingan Waktu Kerja Perhitungan dan Simulasi Koordinasi Proteksi

\begin{tabular}{ccccccc}
\hline \multirow{2}{*}{$\begin{array}{l}\text { Jarak } \\
\text { \%) }\end{array}$} & \multicolumn{2}{c}{ 3 Fasa } & \multicolumn{2}{c}{ 2 Fasa } & \multicolumn{2}{c}{ 1 Fasa } \\
\cline { 2 - 7 } & $\begin{array}{c}\text { Hitung } \\
\text { (detik) }\end{array}$ & $\begin{array}{c}\text { Simulasi } \\
\text { (detik) }\end{array}$ & $\begin{array}{c}\text { Hitung } \\
\text { (detik) }\end{array}$ & $\begin{array}{c}\text { Simulasi } \\
\text { (detik) }\end{array}$ & $\begin{array}{c}\text { Hitung } \\
\text { (detik) }\end{array}$ & $\begin{array}{c}\text { Simulasi } \\
\text { (detik) }\end{array}$ \\
\hline 10 & 0,413 & 0,415 & 0,439 & 0,421 & 0,765 & 0,706 \\
20 & 0,505 & 0,507 & 0,544 & 0,516 & 0,944 & 0,878 \\
30 & 0,596 & 0,599 & 0,651 & 0,612 & 1,117 & 1,038 \\
40 & 0,363 & 0,365 & 0,407 & 0,375 & 0,849 & 0,789 \\
50 & 0,423 & 0,425 & 0,482 & 0,439 & 0,994 & 0,911 \\
60 & 0,489 & 0,493 & 0,331 & 0,511 & 1,146 & 1,018 \\
70 & 0,301 & 0,303 & 0,675 & 0,319 & 0,892 & 0,787 \\
80 & 0,361 & 0,364 & 0,467 & 0,387 & 1,072 & 0,918 \\
90 & 0,436 & 0,441 & 0,589 & 0,473 & 1,309 & 1,068 \\
100 & 0,534 & 0,536 & 0,755 & 0,582 & 1,496 & 1,243 \\
\hline
\end{tabular}


Pada Tabel 14 dari hasil waktu kerja koordinasi antar relai perbandingan nilai arus hubung singkat tiga fasa dan dua fasa perhitungan dan simulasi koordinasi. Nilai keduanya saling berbeda, karena perhitungan yang digunakan menggunakan perhitungan manual dan simulasi dengan software ETAP memiliki metode pembulatan angka yang berbeda, sehingga akan ada perbedaan dari hasil nilai yang di dapat, dari perbedaan perhitungan dan simulasi yang didapat tidak terlalu berbeda jauh.

\section{KESIMPULAN}

Berdasarkan hasil analisis data dan simulasi kerja koordinasi proteksi dengan menggunakan software ETAP pada jaringan distribusi di Gardu Induk Majenang $150 \mathrm{kV}$ yang khususnya pada penyulang (feeder) MJN 08, maka dapat ditarik kesimpulan;

1. Untuk mengetahui nilai arus hubung singkat, langkah yang dilakukan adalah menghitung arus nominal trafo, menghitung reaktansi sumber, menghitung reaktansi trafo, menghitung impedansi saluran penyulang, kemudian menghitung arus hubung singkat

2. Nilai arus gangguan hubung singkat pada jaringan dipengaruhi oleh jarak titik gangguan, semakin dekat jarak pada titik gangguan maka semakin besar pula arus gangguan hubung singkatnya, begitu pula sebaliknya, semakin jauh titik gangguan pada jaringan maka semakin kecil arus gangguannya.

3. Pada simulasi dengan softwere ETAP penyulang MJN 08 Arus hubung singkat terbesar yaitu pada titik gangguan jarak $10 \%$, arus hubung singkat 3 fasa sebesar 5,67 kA, arus hubung singkat 2 fasa sebesar 5,48 kA, dan arus hubung singkat 1 fasa ke tanah sebesar 3,67 kA.

4. Dari penelitian yang di lakukan pada penyulang MJN 08 bahwa waktu kerja koordinasi antar relai OCR arus hubung singkat 3 fasa dan 2 fasa, sudah hampir mendekati dengan standar SPLN yaitu 0,35 detik 0,4 detik. Tapi masih lebih lambat 0,1 detik.

5. Pada perhitungan dan simulasi koordinasi waktu kerja relai GFR arus hubung singkat 1 fasa ke tanah yang di lakukan belum sesuai dengan standar SPLN.

\section{DAFTAR PUSTAKA}

[1] Budi utomo, Heri 2004. Modul Perkuliahan : Proteksi Penyulang Tegangan Menengah. Bandung: Politeknik Negri Bandung.

[2] Marsudi, Djiteng. 2005. Pembangkitan Energi Listrik. Jakarta: Erlangga.

[3] Pandjaitan, Bonar. 2012. Praktik-praktik Proteksi Sistem Tenaga Listrik. Yogyakarta: CV Andi Offset.

[4] SPLN 64:1985, Petunjuk Pemilihan dan Penggunaan Pelebur pada Sistem Distribusi Tegangan Menegah. Jakarta: PT. PLN (Persero).

[5] Yusmartato, yusniati. 2016. Analisis Relai Arus Lebih Dan Relai Gangguan Tanah Pada Penyulang LM5 DI Gardu Induk Lamhotma. Medan: Universitas Isalam Sumatra Utara. 